\title{
Epidemiology, Pathophysiology, and Management of Native Atrioventricular Valve Regurgitation in Heart Failure Patients
}

\author{
Anne-Céline Martin 1,2, Marie-Cécile Bories ${ }^{2,3}$, Noemie Tence ${ }^{3,4}$, Pierre Baudinaud ${ }^{3,5}$, \\ Louis Pechmajou ${ }^{3,4}$, Tania Puscas ${ }^{3,4}$, Eloi Marijon ${ }^{3,5}$, Paul Achouh ${ }^{3,4}$ and Nicole Karam ${ }^{3,4 *}$ \\ ${ }^{1}$ Paris University, INSERM UMRS_1140, Paris, France, ${ }^{2}$ Advanced Heart Failure Unit, European Hospital Georges \\ Pompidou, Paris, France, ${ }^{3}$ University of Paris, PARCC, INSERM, Paris, France, ${ }^{4}$ Heart Valves Unit, European Hospital \\ Georges Pompidou, Paris, France, ${ }^{5}$ Electrophysiology Unit, European Hospital Georges Pompidou, Paris, France
}

\section{OPEN ACCESS}

Edited by:

Michaela M. Hell,

Johannes Gutenberg University

Mainz, Germany

Reviewed by:

Antonino S. Rubino,

University of Campania Luigi

Vanvitelli, Italy

Stefano Ghio,

Fondazione Ospedale San Matteo

(IRCCS), Italy

*Correspondence:

Nicole Karam

nicole.karam@aphp.fr

Specialty section:

This article was submitted to

Heart Valve Disease,

a section of the journal

Frontiers in Cardiovascular Medicine

Received: 23 May 2021

Accepted: 27 September 2021

Published: 25 October 2021

Citation:

Martin A-C, Bories M-C, Tence N, Baudinaud P, Pechmajou L, Puscas T,

Marijon E, Achouh P and Karam N

(2021) Epidemiology, Pathophysiology, and Management of Native Atrioventricular Valve Regurgitation in Heart Failure Patients.

Front. Cardiovasc. Med. 8:713658.

doi: 10.3389/fcvm.2021.713658
Atrioventricular regurgitation is frequent in the setting of heart failure. It is due to atrial and ventricular remodelling, as well as rhythmic disturbances and loss of synchrony. Once atrioventricular regurgitation develops, it can aggravate the underlying heart failure, and further participate and aggravate its own severity. Its presence is therefore concomitantly a surrogate of advance disease and a predictor of mortality. Heart failure management, including medical therapy, cardiac resynchronization therapy, and restoration of sinus rhythm, are the initial steps to reduce atrioventricular regurgitation. In the current review, we analyse the current data assessing the epidemiology, pathophysiology, and impact of non-valvular intervention on atrioventricular regurgitation including medical treatment, cardiac resynchronization and atrial fibrillation ablation.

Keywords: mitral regurgitation, heart failure, tricuspid regurgitation, heart-drug effects, resynchronization therapy, atrial fibrillation ablation

\section{INTRODUCTION}

Chronic atrioventricular valves regurgitation, whether mitral or tricuspid, is highly prevalent in the general population, and in the setting of heart failure (HF). Mitral regurgitation (MR) is currently the most common type of moderate-to-severe valve disease in the general adult population, partly due to the increase in the prevalence of treated cardiomyopathies and HF (1). Indeed, current statistics indicate that HF affects around 23 million people worldwide (2). Data from the prospective European Society of Cardiology Heart Failure Long-Term (ESC-HF-LT) Registry estimate that moderate-to-severe secondary MR is present in $36 \%$ of patients with HF with reduced ejection fraction (HFrEF), $28 \%$ with HF with mid-range ejection fraction, and 20\% with HF with preserved ejection fraction (3).

The presence of secondary MR in patients with HFrEF is associated with HF symptoms, increased hospitalisation rates, and worse prognosis. Severe secondary MR is a major mortality predictor, independent of clinical and echocardiographic confounders, with an increase in mortality rate by $76 \%$ compared to the absence of MR (4). Beyond being a surrogate of advanced cardiac disease, the presence of MR is considered as an aggravating factor $(5,6)$.

Similarly, tricuspid regurgitation (TR) is recognised as a common valve disease, observed in more than 1.6 million individuals in the United States. More than $80 \%$ of TR encountered in clinical practise is secondary, related to either left-sided valvular diseases, chronic atrial fibrillation, 
or global heart failure. In the ESC-HF-LT Registry moderate to severe TR was equally prevalent among HF subtypes, affecting approximately $20 \%$ of the patients with HF (3). In a large cohort of patients with HFrEF, increasing TR severity was independently associated with considerably worse prognosis. Five-year survival was only $45 \pm 2 \%$ for moderate TR, and $34 \pm 4 \%$ for severe TR (7). Interestingly, the independent impact of TR on mortality was sustained whatever the ejection fraction was (8).

\section{MITRAL REGURGITATION}

\section{Pathophysiology}

The association of MR and HF is complex. While chronic MR can induce HF, HF can lead to progressive MR (Figure 1).

During systole, the closure of the mitral leaflets results from the interaction of closing forces (transmitral pressure gradient) and the opposing tethering forces determined by left ventricular (LV) systolic pressure. In patients with chronic HF, progressive LV remodelling induces changes in the geometry, volume and function of the LV and papillary muscle displacement, often associated with progressive annular dilation and flattening, all contributing to the development of secondary MR. Besides, focal regional LV contraction abnormalities induced by myocardial ischemia or infarction, or left bundle branch block (LBBB) can amplify the phenomenon. In the first case, desynchrony of myocardium surrounding the papillary muscles accounts for the progression of MR (9), whereas LBBB induces a delayed contraction between the segment next to anterolateral papillary muscle and the inferior segment, which results in changes in mitral tethering forces and MR, which in turn exacerbates the LV dilation. Remodelling also affects the left atrium through both the presence of MR itself, and HF-associated atrial fibrillation. Left atrial enlargement relocates the posterior mitral annulus portion and induces tethering of the posterior mitral leaflet, again increasing MR severity. Atrial fibrillation alters LV filling through the loss of atrial contraction and atrioventricular synchrony, further aggravating HF signs (10). Overall, the mechanism of MR in chronic HF combines Carpentier types I and IIIb (Figure 2). The respective part of LV damage and MR severity in HF has been presented in a new conceptual framework defined by Grayburn and al., and distinguishing, according to estimated regurgitant orifice area (EROA)/LV end diastolic volume (LVEDV) ratio, MR-dominant disease, also called "disproportionate MR," from MR-LV-co-dominant, also referred to as "proportionate MR," and LV-dominant, also referred to as "non-severe MR" (11).

The specificity of secondary MR in patients with HFrEF is that it is a dynamic condition, affected by changes in loading conditions, pressure or volume. Serial evaluations of MR in a given patient often reveals different degrees of severity according to the patient's status.

In the absence of underlying cardiomyopathy, patients with long-standing primary MR can develop progressive HF over time. The mechanism of $\mathrm{HF}$ in this case is a maladaptive remodelling, which changes the geometry, volume and function of the LV and induces papillary muscle displacement. This again will sustain and increase the severity of MR by creating a mixed-type $M R$, combining both the original primary $M R$ and a secondary MR, through the mechanisms cited above.

\section{Therapeutic Options}

Management of MR in the setting of HF depends on its underlying mechanism. In cases of primary MR leading to HF, surgical or percutaneous treatment of the mitral valve can lead to an improvement or stabilisation of HF at early stages. In the absence of early treatment, myocardial damage might become irreversible and therefore, the management will also conventional HF therapy.

\section{Medical Treatment}

By reversing LV remodelling, medical treatment may secondarily reduce MR severity. The cornerstone of conventional medical treatment for HFrEF involves, on top of diuretics for acute decompensations, neurohormonal therapies targeting the inhibition of the sympathetic nervous system (beta-blockers) and the renin-angiotensin-aldosterone system (RAAi), including angiotensin-converting enzyme inhibitor (ACEI), angiotensin receptor blocker (ARB), and mineralocorticoid receptor antagonist (MRA), and neprilysin inhibition with the association of sacubitril and valsartan (12). All these therapies were proven to improve HF outcome and severity. However, very few studies have specifically examined their effect on secondary MR.

Most of the data comes from beta-blockers, in particular carvedilol and metoprolol. In a double-blind randomised trial of patients with HFrEF and ischemic or dilated cardiomyopathy, metoprolol reduced LV volumes, improved LV function, and decreased mitral regurgitation in $42 \%$ of the 128 metoprololtreated patients at 6 months, vs. $20 \%$ of the placebo-group patients (13). In 257 patients with HFrEF, carvedilol reduced the severity of MR over a 2-years follow-up in 30\% of the patients. These effects were most pronounced in patients LV end-diastolic diameter $>37 \mathrm{~mm} / \mathrm{m}^{2}$ (14). Finally, carvedilol reduced EROA by $80 \%$ at 6 months in 45 patients with severe $\mathrm{MR}(\mathrm{EROA}=0.6$ $\mathrm{cm}^{2}$ ) and LV diastolic diameter above $75 \mathrm{~mm}$ (15).

Less has been reported on the ability of RAAi to reduce MR in HFrEF. A small study ( $\mathrm{n}=19$ patients) showed that up-titration of lisinopril and isosorbide dinitrate in patients receiving digoxin and diuretics reduced LV end-diastolic volume leading to a MR reduction to grade $0 / 1$ in $42 \%$ of patients with baseline severe MR at 1-year follow-up (16).

More recently, the double-blind randomised controlled trial PRIME (Pharmacological Reduction of Functional Ischemic Mitral Regurgitation) including 118 patients with HFrEF and secondary MR reported a significant reduction in both the $\mathrm{LV}$ end-diastolic volume and the degree of MR, as estimated by EROA and regurgitant volume, with sacubitril/valsartan, compared with valsartan at 12 months (17). Similarly, in a single centre study, switching therapy in HFrEF patients from a RAAi to sacubitril/valsartan induces beneficial reverse remodelling on LV volume and LV function at a median follow-up of 118 (77160) days and was associated with a reduction in the degree of $\operatorname{MR}(18)$. 


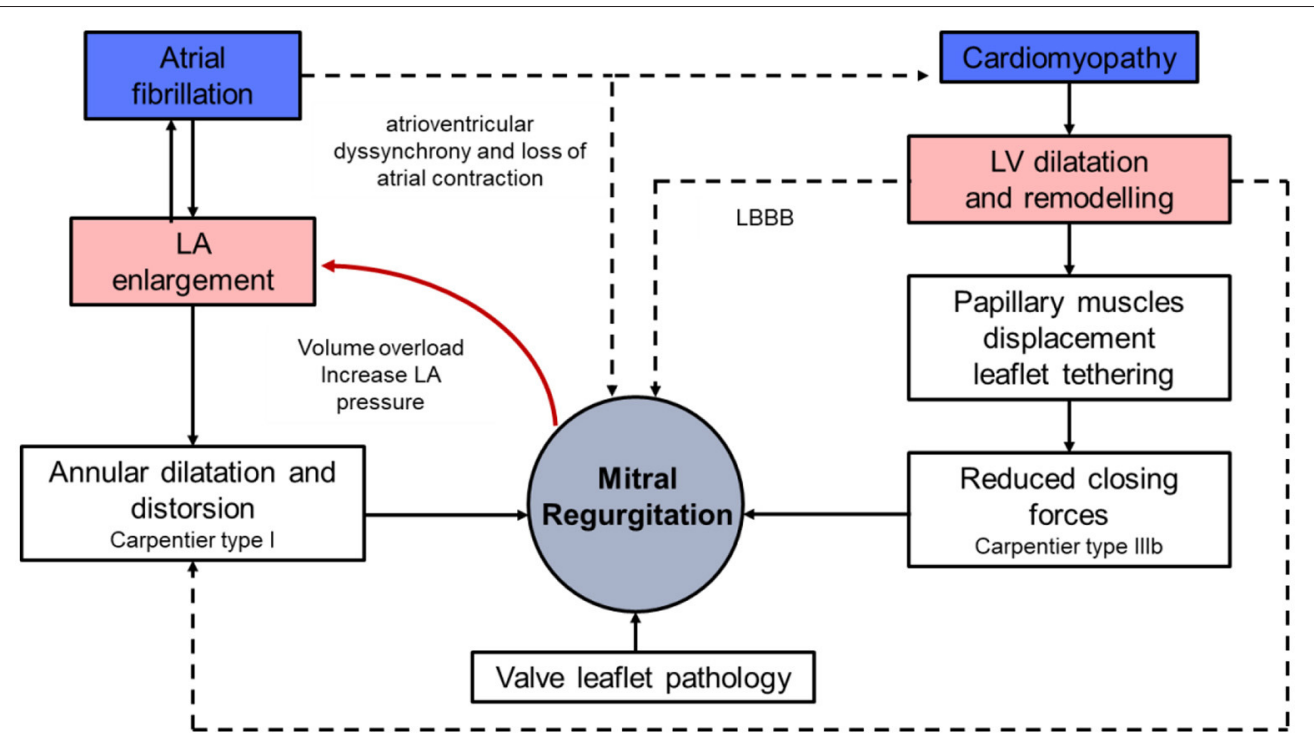

FIGURE 1 | Pathophysiology of mitral regurgitation and heart failure. LA, left atrium; LV, left ventricle; LBBB, left bundle branch block.

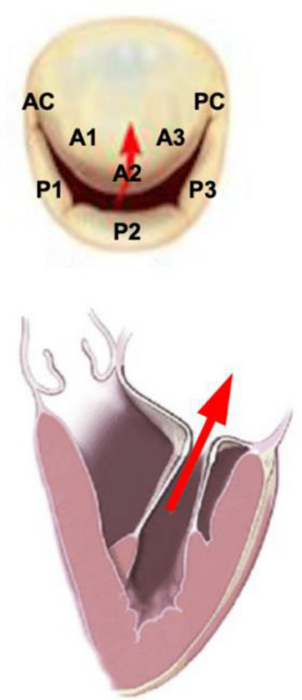

Type I
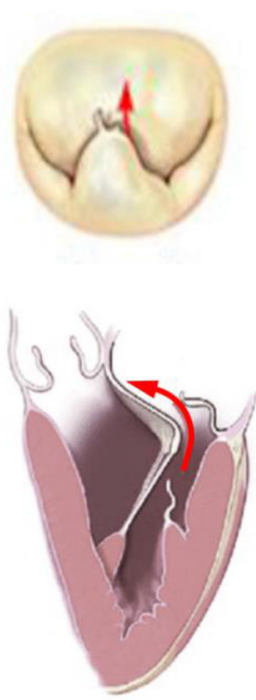

Type II
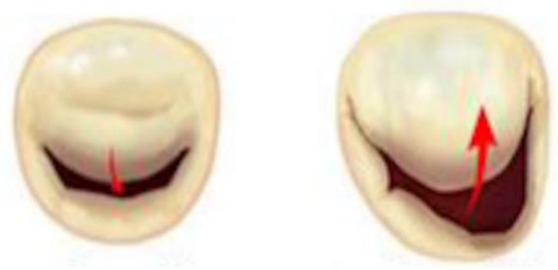

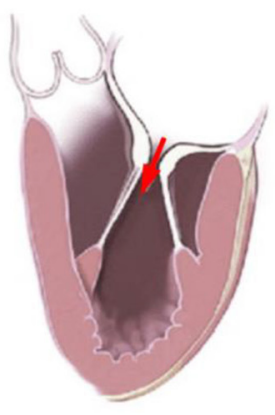

Type Illa

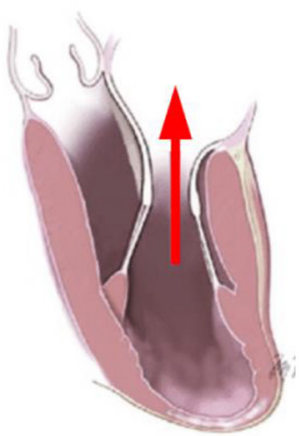

Type IIIb

FIGURE 2 | Carpentier classification for mitral valve regurgitation.

Overall, the effect of medical treatment combination on secondary MR reduction has been proven in a prospective study of 163 patients with HFrEF, whose treatment included ACEI or $\mathrm{ARB}$ in $85 \%$ of cases (55\% receiving an optimal dose), betablocker in 94\% (59\% at optimal dose) and MRA in 43\% (55\% at optimal dose). Moderate or severe MR was present at baseline in $31 \%$ of the patients. Among those, 38\% experienced a decrease in MR to a non-severe grade at 4 years (19). In a sub-analysis of the Cardiovascular Outcomes Assessment of the MitraClip
Percutaneous Therapy for Heart Failure Patients with Functional MR (COAPT) trial comparing percutaneous mitral repair to optimal medical treatment in patients with $3+$ or $4+$ secondary $\mathrm{MR}$, a reduction in MR severity to $<2+$ was seen in $34 \%$ of the 614 participants who were randomised to medical treatment (20).

Regarding other treatments recommended in selected patients with HFrEF, the SHIFT echocardiographic sub-study suggested a potential MR reduction with Ivabradine but failed in reaching significancy, despite a plausible pathophysiological rational 


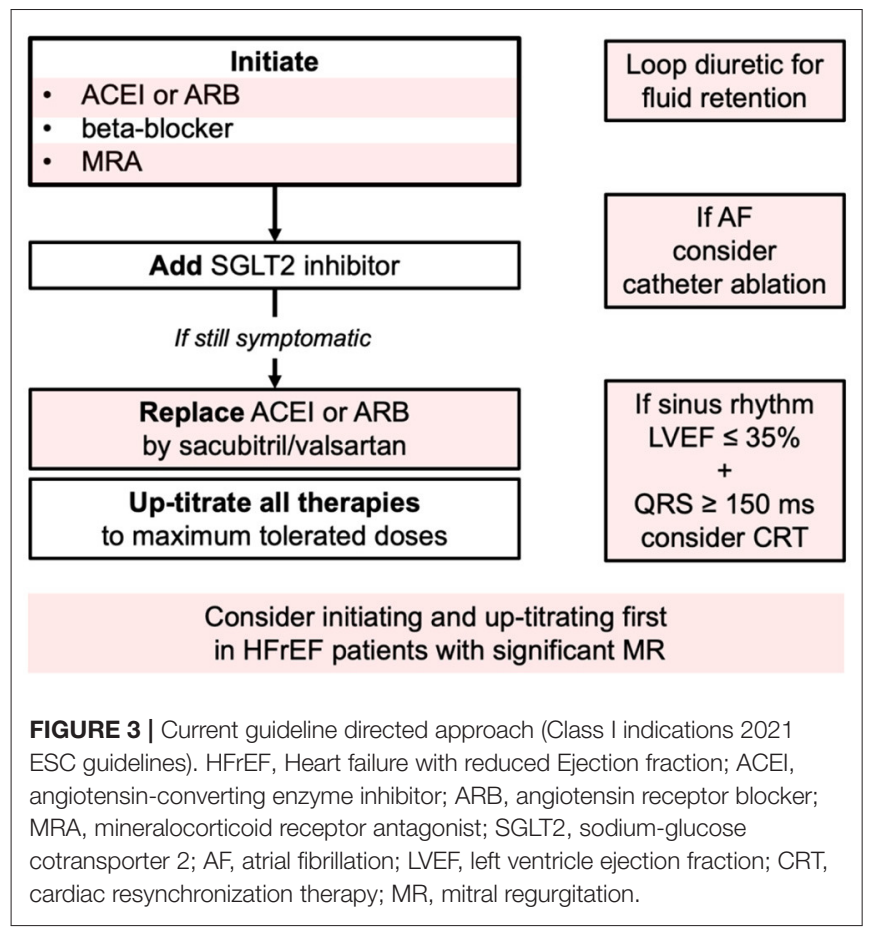

related to LV remodelling (21). Other drugs, such as sodiumglucose cotransporter 2 (SGLT2) inhibitors and Vericiguat, a soluble guanylate cyclase stimulator, have recently joined the arsenal of HF therapy. Their benefit on LV or left atrial remodelling, and therefore on MR reduction, has not been clearly demonstrated yet.

According to the recent 2021 ESC Guidelines on the diagnosis and treatment of acute and chronic heart failure, the triad of an ACEI/sacubitril-valsartan, a beta-blocker, and an MRA is recommended as cornerstone therapies for HFrEF patients (22). These drugs should be uptitrated to the maximally tolerated doses. SGLT2 inhibitors are now recommended for all patients with HFrEF already treated with the triad regardless of whether they have diabetes or not. However, full treatment initiation is sometimes not well-tolerated, and treatments have to be introduced sequentially and progressively uptitrated. Ones suggest simultaneous initiation of treatment with a beta-blocker and an SGLT2 inhibitors, followed by addition of sacubitril/valsartan few weeks later, then MRA (Figure 3) (23). Since RAAi and sacubitril/valsartan were associated with a significant MR severity reduction, we would first suggest upgrading these molecules for patients with HFrEF and secondary MR. This proposal has to be validated in further studies.

\section{Cardiac Resynchronization Therapy}

Cardiac resynchronization therapy (CRT) is recommended for patients in sinus rhythm with $\mathrm{LVEF} \leq 35 \%$, a QRS duration $\geq 130 \mathrm{~ms}$ (Class IIa) or $\geq 150 \mathrm{~ms}$ (Class I) and LBBB morphology who remain symptomatic despite OMT in order to improve symptoms and reduce morbidity and mortality (12). Several
TABLE 1 | Studies evaluating MR reduction after CRT implantation.

\begin{tabular}{lll}
\hline Study & $\begin{array}{l}\text { No. of patients } \\
\text { CRT-on/No. of } \\
\text { patients in the study }\end{array}$ & $\begin{array}{l}\text { \% MR reduction } \\
\text { ( } \boldsymbol{p} \text {-value) follow-up }\end{array}$ \\
\hline Cleland et al. (25) & $409 / 813$ & $34 \%(<0.05)$ at 3 M \\
Abraham et al. (26) & $172 / 373$ & $29 \%(<0.05)$ at 3 M \\
Cazeau et al. (27) & $34 / 131$ & $23 \%(<0.05)$ at $6 \mathrm{M}$ \\
Cabrera-Bueno et al. (28) & $34 / 176$ & $18 \%(=0.189)$ at $12 \mathrm{M}$ \\
Di Biase et al. (29) & $275 / 794$ & $\mathrm{MR}$ improvement in \\
& & $46 \%<0.0001$ \\
Verhaert et al. (30) & $266 / 266$ & $23 \%(<0.0001)$ at $6 \mathrm{M}$ \\
Van Bommel et al. (31) & $98 / 98$ & $20 \%(<0.001)$ at $6 \mathrm{M}$ \\
Sitges et al. (32) & $57 / 151$ & $41 \%(<0.01)$ at $12 \mathrm{M}$
\end{tabular}

studies assessing the yield of CRT on top of optimal medical treatment I HF patients showed a sustained reduction in MR severity with CRT (24-32) (Table 1). CRT acts through two different mechanisms. The first one is immediate, related to a more coordinated contraction of papillary muscle-bearing segments, leading to a decreased tethering. The early impact of CRT on MR decrease has been confirmed in a study by Brandt et al. that demonstrated that a 72-h cessation of long-term CRT led to a decline in LV systolic performance and an increase in secondary MR assessed by echocardiography (EROA 9.1 vs. 4.8 $\mathrm{mm}^{2}, p<0.0001$, mitral regurgitant volume 16.0 vs. $7.8 \mathrm{~mL}, p$ $<0.0001)$ (33). The second mechanism of MR reduction after CRT occurs weeks to months after CRT implantation, and is due to reverse LV remodelling and restoration of synchronous ventricular contraction, thus increasing the closing forces and diminishing the mitral valve leaflet tethering, all facilitating leaflets coaptation $(34,35)$. The Cardiac ResynchronizationHeart Failure (CARE-HF) trial demonstrated a 37\% reduction in death from any cause and cardiac hospitalisation in patients with HFrEF with CRT on top of optimal medical treatment. It also showed an MR reduction as illustrated by a reduction in EROA with a significant mean difference of $-0.05 \mathrm{~cm}^{2}$ at 3 and $-0.04 \mathrm{~cm}^{2}$ at 18 months (25). Of note, MR grade at 3 months was an independent predictor of survival. In the Multicenter InSync Randomised Clinical Evaluation (MIRACLE) trial including 450 patients with LVEF $<35 \%$, QRS duration $>130 \mathrm{~ms}$, CRT resulted in marked and sustained MR reduction. Mean area of the mitral regurgitant jet was $7.6 \mathrm{~cm}^{2}$ at baseline and median change reached $-2.7 \mathrm{~cm}^{2}$ with CRT (26). In two studies on 85 and 240 patients with grade $3+/ 4+$ MR, MR severity reduction was observed in $49 \%$ and $42 \%$ of the patients at 6 months, respectively $(30,35)$, while it remained stable in $37 \%$ and worsened in $21 \%$ in the second study.

Interestingly, persistent MR after CRT was strongly associated with poor outcomes (36). Indeed, van der Bijl et al. assessed MR severity evolution in 1,313 patients treated with CRT and defined 4 patterns (37). Of the 518 patients with moderate to severe MR at baseline, MR improved to no or mild MR in 209 $(40 \%)$ and remained unchanged in $309(60 \%)$ at 6 months, the latter group having the highest mortality rates, followed by those with worsened MR severity from no or mild MR at baseline 
to moderate to severe MR at 6 months. Baseline moderate to severe MR that remained unchanged at 6 months after CRT was independently associated with increased risk of mortality [hazard ratio 1.77 (1.41-2.22), $p<0.001]$.

Predictors of MR reduction after CRT are not known. However, patients with higher baseline MR severity are more likely to present with MR improvement after CRT. Moreover, considering the recent proportionality concept, Packer and Grayburn suggested that LBBB-associated intraventricular conduction delay characterises patients with disproportionate $\mathrm{MR}$, and those patients might be better candidates for CRT, even though this concept remains to be proven (38). Since MR improvement at 3-month predicts CRT response and MR improvement at 12-month, Di Biase et al. suggested that interventional strategy should be proposed when MR persists at 3 months after CRT (29).

\section{Cardioversion and Catheter Ablation of Atrial Fibrillation}

Atrial fibrillation-induced left atrial and annular enlargement lead to atrial MR development or worsening, and further atrial remodelling and fibrosis that perpetuate atrial fibrillation and $\mathrm{MR}(39,40)$. Therefore, restoration of sinus rhythm, through pharmacological measures, cardioversion or catheter ablation, might be needed to break the vicious circle. Dell'Era et al. demonstrated that sinus rhythm restauration by electric cardioversion in 73 patients with atrial fibrillation reduced MR severity through reverse LA remodelling and favourable effect on LV function that appears modulated by the atrium itself (41).

Several studies demonstrated that catheter ablation for atrial fibrillation reduce mortality and HF hospitalisation in HFrEF $(42,43)$, as well as secondary MR severity $(44,45)$. Importantly, in these studies, MR corresponds to "atrial MR," which complicate $3-15 \%$ of chronic atrial fibrillation. Kawaji et al. observed in a retrospective study of 280 patients with LVEF $<50 \%$ that atrial fibrillation catheter ablation improved several cardiac anomalies including LV dysfunction and left atrial dilation. MR was also significantly reduced, with only $37 \%$ of patients with moderate to severe MR at baseline having unchanged MR severity 5 years after catheter ablation (44). Similarly, Wu et al. recently showed in a small cohort including 54 patients a significant reduction in MR severity, left atrium size and LV volumes and function after restoring sinus rhythm with catheter ablation in patients with LV systolic dysfunction (45). Moderate to severe MR incidence rate decreased from $55.5 \%$ at baseline to only $11.1 \%$ after ablation ( $p$ $=0.007$ ). Of note, atrial enlargement was the main mechanism of MR in these studies, since baseline characteristics showed left atrium size $>40 \mathrm{~mm}$ in $80 \%$ of them but LVEF $<40 \%$ in only $30 \%$.

\section{TRICUSPID REGURGITATION}

\section{Pathophysiology}

The mechanism of secondary TR in HF patients is complex and often multifactorial, frequently combining the effects of both right ventricular (RV) and right atrial dilatation (Figure 4).

The first mechanism relies on valvular leaflet tethering and restricted motion induced by RV dilatation. Indeed, left-sided HF causes increased LV filling pressures, with subsequent reduction in pulmonary artery compliance, pulmonary hypertension and overload in the RV. This leads to the dilation of right cardiac cavities and tricuspid annulus creating the substratum for TR. Since TR worsens with RV dilatation, overload promotes a vicious circle of RV failure in patients with TR and left-sided HFrEF. The second mechanism relies on tricuspid annulus dilatation as a result of the enlargement of the right atrium extending to the RV, which may result in loss of coaptation or malalignment of the leaflets then worsening of TR (46). Of note, in both situations, pacemaker and internal defibrillator leads implanted as part of HF treatment, might participate in the development or the worsening of TR (47).

\section{Therapeutic Options}

It is mandatory to assess the characteristics of right chamber remodelling and the two types of secondary TR mechanisms for a better understanding of the pathological process leading to TR and, further, for individualising therapeutic management.

Medical treatment options for TR are very limited. Specific treatment goals include optimization of preload and afterload, and maintenance of sinus rhythm and atrioventricular synchrony.

Loop diuretics may improve symptoms while pulmonary vasodilators may lead to a reduction in TR severity. Given the dynamic behaviour of TR, like secondary MR, a transient improvement in TR severity can be observed after depletion and reduction of volume overload. In contrast, the benefit of classical HF treatments in improving TR severity is not established. ACEI has been shown to increase right ventricular ejection fraction and to reduce right ventricle end-diastolic volume and filling pressures (48). Small studies have also demonstrated that betablockers including carvedilol and bisoprolol improve RV systolic function (49). Some evidence supports the benefit of sinus rhythm restoration on the reduction of TR severity $(50,51)$. However, these studies have been performed in patients with concomitant MR and preserved ejection fraction, and whether the improvement is due to a direct impact on TR per se or to an improvement in MR and left heart characteristics is unknown.

\section{PERSPECTIVES}

While the benefit of optimal medical treatment including CRT in the management of HFrEF is well-established, data show that $50 \%$ of patients respond favourably in terms of MR severity reduction (38). In case of persistent $\mathrm{MR}$ and unsatisfactory result of optimised medical treatment, more specific therapies should be considered.

Mitral repair with edge-to-edge percutaneous procedures can be proposed. According to the 2021 ESC/EACTS Guidelines for the management of valvular heart disease, it should be considered in selected symptomatic patients, not eligible for surgery and fulfilling criteria suggesting an increased chance of responding to the treatment (Class IIa) $(22,52)$. In high-risk symptomatic patients not eligible for surgery and not fulfilling the criteria suggesting an increased chance of responding to transcatheter edge-to-edge repair, the Heart Team may consider in selected 


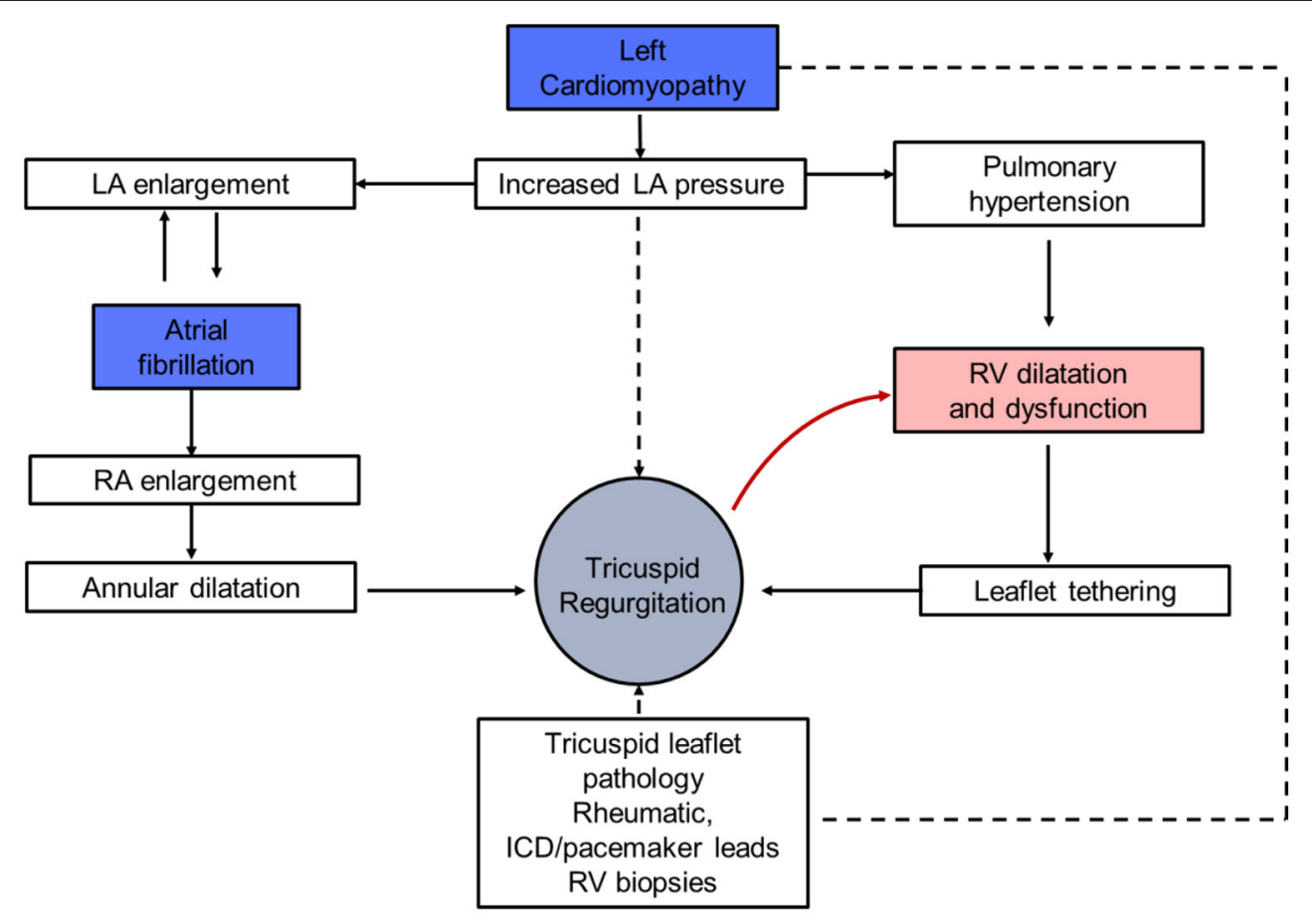

FIGURE 4 | Pathophysiology of tricuspid regurgitation and heart failure. LA, left atrium; RA, right atrium; RV, right ventricle; ICD, implantable cardioverter defibrillator.

cases a transcatheter edge-to-edge repair procedure or other transcatheter valve therapy if applicable, after careful evaluation for left ventricular assist device or heart transplantation. Similarly, transcatheter treatment of symptomatic secondary severe TR may be considered in inoperable patients at a Heart Valve Centre with expertise in the treatment of tricuspid valve disease. Specific treatment of TR can improve HF symptoms and right ventricular function and dimensions, as well as liver function (53-55). When TR coexists, concomitant edge-to-edge repair of the tricuspid valve in patients combining MR and TR can also be considered, knowing that it was associated with higher 1-year survival rate compared with isolated mitral repair in patients with both MR and TR $(56,57)$.

Left ventricle assist device (LVAD) should also be discussed early as destination therapy or as a bridge to transplantation due to its benefit on survival, functional state and quality of life (58). LVAD implantation also has drastic effects on LV remodelling leading to the reduction of LV volumes and the improvement of MR (59). It is particularly attractive in LV-dominant MR, when patients with end stage HFrEF and INTERMACS 2 to 4 status remain symptomatic despite optimal medical treatment and CRT (60) since the benefit of mitral repair seems limited. Indeed, following LVAD support, more than $80 \%$ of patients with severe MR show an improvement in MR to a level that is no longer clinically meaningful $(61,62)$. LVAD may also improve TR (63). Both recent 2021 Guidelines on valvular heart disease and those on heart failure agree on the necessity of considering LVAD and/or heart transplantation before considering transcatheter edge-to-edge repair in high-risk symptomatic patients with severe secondary MR and end-stage LV dysfunction (and/or RV function), not eligible for surgery and not fulfilling the criteria suggesting an increased chance of responding to transcatheter edge-to-edge repair $(22,52)$.

Data from the European Registry for Patients with Mechanical Circulatory Support (EUROMACS) report in 2,496 patients with LVAD support, that TR decreases immediately after implant by $\sim 65 \%$ from moderate-to-severe TR pre-LVAD to non-tomild TR (64). However, since moderate-to-severe TR before LVAD implantation is independently associated with poor outcomes, whether TR should be repaired before LVAD is under discussion.

\section{CONCLUSION}

Non-invasive strategies including optimal medical treatment, sinus rhythm restoration in the presence of atrial fibrillation, and CRT in the case of LBBB are the first and crucial but often insufficient steps in HF patients with secondary MR or TR. The decision pathway for the management of secondary MR has been well-defined in the recent updated guidelines $(22,52)$. The role of heart teams composed of valve specialists, interventional cardiologists, cardiac surgeons, multimodality imaging experts, anesthesiologists and heart failure specialists is paramount in selecting the appropriate therapy for the appropriate patient. Patients have to be assessed in their entirety, taking into account the type of atrioventricular valve disease, its mechanism, the underlying myocardiopathy and the patient wishes and expectations. 


\section{AUTHOR CONTRIBUTIONS}

$\mathrm{NK}$ and A-CM drafted the original manuscript. M-CB, NT, PB, LP, TP, EM, and PA reviewed the

\section{REFERENCES}

1. Nkomo VT, Gardin JM, Skelton TN, Gottdiener JS, Scott CG, EnriquezSarano M. Burden of valvular heart diseases: a population-based study. Lancet. (2006) 368:1005-11. doi: 10.1016/S0140-6736(06)69208-8

2. Savarese G, Lund LH. Global public health burden of heart failure. Card Fail Rev. (2017) 3:7-11. doi: 10.15420/cfr.2016:25:2

3. Chioncel O, Lainscak M, Seferovic PM, Anker SD, Crespo-Leiro MG, Harjola VP, et al. Epidemiology and one-year outcomes in patients with chronic heart failure and preserved, mid-range and reduced ejection fraction: an analysis of the ESC heart failure long-term registry. Eur J Heart Fail. (2017) 19:1574-85. doi: 10.1002/ejhf.813

4. Goliasch G, Bartko PE, Pavo N, Neuhold S, Wurm R, Mascherbauer J, et al. Refining the prognostic impact of functional mitral regurgitation in chronic heart failure. Eur Heart J. (2018) 39:39-46. doi: 10.1093/eurheartj/ehx402

5. Obadia JF, Messika-Zeitoun D, Leurent G, Iung B, Bonnet G, Piriou N, et al. Percutaneous repair or medical treatment for secondary mitral regurgitation. N Engl J Med. (2018) 379:2297-306. doi: 10.1056/NEJMoa1805374

6. Stone GW, Lindenfeld J, Abraham WT, Kar S, Lim DS, Mishell JM, et al. Transcatheter mitral-valve repair in patients with heart failure. $N$ Engl J Med. (2018) 379:2307-18. doi: 10.1056/NEJMoa1806640

7. Benfari G, Antoine C, Miller WL, Thapa P, Topilsky Y, Rossi A, et al. Excess mortality associated with functional tricuspid regurgitation complicating heart failure with reduced ejection fraction. Circulation. (2019) 140:196206. doi: 10.1161/CIRCULATIONAHA.118.038946

8. Ren QW, Li XL, Fang J, Chen Y, Wu MZ, Yu YJ, et al. The prevalence, predictors, and prognosis of tricuspid regurgitation in stage $\mathrm{B}$ and $\mathrm{C}$ heart failure with preserved ejection fraction. ESC Heart Fail. (2020) 7:405160. doi: 10.1002/ehf2.13014

9. Donal E, De Place C, Kervio G, Bauer F, Gervais R, Leclercq C, et al. Mitral regurgitation in dilated cardiomyopathy: value of both regional left ventricular contractility and dyssynchrony. Eur J Echocardiogr. (2009) 10:1338. doi: 10.1093/ejechocard/jen188

10. Chiocchini A, Terricabras M, Verma A. Atrial fibrillation ablation in heart failure: what do we know? What can we do? Europace. (2021) 23:35361. doi: 10.1093/europace/euaa217

11. Grayburn PA, Sannino A, Packer M. Distinguishing proportionate and disproportionate subtypes in functional mitral regurgitation and left ventricular systolic dysfunction. JACC Cardiovasc Imaging. (2021) 14:7269. doi: 10.1016/j.jcmg.2020.05.043

12. Ponikowski P, Voors AA, Anker SD, Bueno H, Cleland JGF, Coats AJS, et al. 2016 ESC guidelines for the diagnosis treatment of acute chronic heart failure: the task force for the diagnosis treatment of acute chronic heart failure of the european society of cardiology (ESC)developed with the special contribution of the heart failure association (HFA) of the ESC. Eur Heart J. (2016) 37:2129-200. doi: 10.1093/eurheartj/ehw128

13. Waagstein F, Strömblad O, Andersson B, Böhm M, Darius M, Delius W, et al. Increased exercise ejection fraction and reversed remodeling after long-term treatment with metoprolol in congestive heart failure: a randomized, stratified, double-blind, placebo-controlled trial in mild to moderate heart failure due to ischemic or idiopathic dilated cardiomyopathy. Eur J Heart Fail. (2003) 5:679-91. doi: 10.1016/S1388-9842(03)00105-3

14. Arnold JM, Yusuf S, Young J, Mathew J, Johnstone D, Avezum A, Lonn E, et al. Prevention of heart failure in patients in the heart outcomes prevention evaluation (HOPE) study. Circulation. (2003) 107:128490. doi: 10.1161/01.CIR.0000054165.93055.42

15. Lowes BD, Gill EA, Abraham WT, Larrain JR, Robertson AD, Bristow MR, et al. Effects of carvedilol on left ventricular mass, chamber geometry, and mitral regurgitation in chronic heart failure. Am J Cardiol. (1999) 83:12015. doi: 10.1016/S0002-9149(99)00059-4 manuscript, provided comments, and suggested modifications to the manuscript. All authors contributed to the article and approved the submitted version.
16. Levine $\mathrm{TB}$, Levine $\mathrm{AB}$, Keteyian SJ, Narins B. The impact of betareceptor blocker addition to high-dose angiotensin-converting enzyme inhibitor-nitrate therapy in heart failure. Clin Cardiol. (1998) 21:899904. doi: $10.1002 /$ clc.4960211208

17. Kang DH, Park SJ, Shin SH, Hong GR, Lee S, Kim MS, et al. Angiotensin receptor neprilysin inhibitor for functional mitral regurgitation. Circulation. (2019) 139:1354-65. doi: 10.1161/CIRCULATIONAHA.118.037077

18. Martens P, Beliën $H$, Dupont M, Vandervoort P, Mullens W. The reverse remodeling response to sacubitril/valsartan therapy in heart failure with reduced ejection fraction. Cardiovasc Ther. (2018) 36:e12435. doi: 10.1111/1755-5922.12435

19. Nasser R, Van Assche L, Vorlat A, Vermeulen T, Van Craenenbroeck E, Conraads V, et al. Evolution of functional mitral regurgitation and prognosis in medically managed heart failure patients with reduced ejection fraction. JACC Heart Fail. (2017) 5:652-9. doi: 10.1016/j.jchf.2017.06.015

20. Kar S, Mack MJ, Lindenfeld JA. Relationship Between Residual Mitral Regurgitation and Clinical and Functional Outcomes in the COAPT Trial. Paris: EuroPCR (2019).

21. Tardif JC, O'Meara E, Komajda M, Böhm M, Borer JS, Ford I, et al. Effects of selective heart rate reduction with ivabradine on left ventricular remodelling and function: results from the SHIFT echocardiography substudy. Eur Heart J. (2011) 32:2507-15. doi: 10.1093/eurheartj/ehr311

22. McDonagh TA, Metra M, Adamo M, Gardner RS, Baumbach A, Böhm M, et al. 2021. ESC guidelines for the diagnosis and treatment of acute and chronic heart failure. Eur Heart J. (2021) 42:3599-726. doi: 10.1093/eurheartj/ehab368

23. McMurray JJV, Packer M. how should we sequence the treatments for heart failure and a reduced ejection fraction?: a redefinition of evidence-based medicine. Circulation. (2021) 143:875-7. doi: 10.1161/CIRCULATIONAHA.120.052926

24. Spartera M, Galderisi M, Mele D, Cameli M, D'Andrea A, Rossi A, et al. Echocardiographic study group of the italian society of cardiology (SIC). Role of cardiac dyssynchrony and resynchronization therapy in functional mitral regurgitation. Eur Heart J Cardiovasc Imaging. (2016) 17:47180. doi: 10.1093/ehjci/jev352

25. Cleland JG, Daubert JC, Erdmann E, Freemantle N, Gras D, Kappenberger L, et al. The effect of cardiac resynchronization on morbidity and mortality in heart failure. N Engl J Med. (2005) 352:1539-49. doi: 10.1056/NEJMoa050496

26. Abraham WT, Fisher WG, Smith AL, Delurgio DB, Leon AR, Loh E, et al. Multicenter InSync randomized clinical evaluation. cardiac resynchronization in chronic heart failure. N Engl J Med. (2002) 346:184553. doi: 10.1056/NEJMoa013168

27. Cazeau S, Leclercq C, Lavergne T, Walker S, Varma C, Linde C, et al. Effects of multisite biventricular pacing in patients with heart failure and intraventricular conduction delay. N Engl J Med. (2001) 344:87380. doi: 10.1016/S1062-1458(01)00399-3

28. Cabrera-Bueno F, Molina-Mora MJ, Alzueta J, Pena-Hernandez J, JimenezNavarro M, Fernandez-Pastor J, et al. Persistence of secondary mitral regurgitation and response to cardiac resynchronization therapy. Eur J Echocardiogr. (2010) 11:131-7. doi: 10.1093/ejechocard/jep184

29. Di Biase L, Auricchio A, Mohanty P, Bai R, Kautzner J, Pieragnoli P, et al. Impact of cardiac resynchronization therapy on the severity of mitral regurgitation. Europace. (2011) 13:829-38. doi: 10.1093/europace/eur047

30. Verhaert D, Popovic ZB, De S, Puntawangkoon C, Wolski K, Wilkoff $\mathrm{BL}$ et al. Impact of mitral regurgitation on reverse remodeling and outcome in patients undergoingcardiac resynchronization therapy. Circ Cardiovasc Imaging. (2012) 5:21-6. doi: 10.1161/CIRCIMAGING.111.96 6580

31. van Bommel RJ, Marsan NA, Delgado V, Borleffs CJ, van Rijnsoever EP, Schalij MJ, et al. Cardiac resynchronization therapy as a therapeutic option in patients 
with moderate-severe functional mitral regurgitation and high operative risk. Circulation. (2011) 124:912-9. doi: 10.1161/CIRCULATIONAHA.110.009803

32. Sitges M, Vidal B, Delgado V, Mont L, Garcia-Alvarez A, Tolosana JM et al. Long-term effect of cardiac resynchronization therapy on functional mitral valve regurgitation. Am J Cardiol. (2009) 104:3838. doi: 10.1016/j.amjcard.2009.03.060

33. Brandt RR, Reiner C, Arnold R, Sperzel J, Pitschner HF, Hamm CW. Contractile response and mitral regurgitation after temporary interruption of long-term cardiac resynchronization therapy. Eur Heart J. (2006) 27:18792. doi: 10.1093/eurheartj/ehi558

34. Breithardt OA, Stellbrink C, Herbots L, Claus P, Sinha AM, Bijnens B, et al. Cardiac resynchronization therapy can reverse abnormal myocardial strain distribution in patients with heart failure and left bundle branch block. J Am Coll Cardiol. (2003) 42:486-94. doi: 10.1016/S0735-1097(03)00709-5

35. Breithardt OA, Sinha AM, Schwammenthal E, Bidaoui N, Markus KU, Franke A, et al. Acute effects of cardiac resynchronization therapy on functional mitral regurgitation in advanced systolic heart failure. J Am Coll Cardiol. (2003) 41:765-70. doi: 10.1016/S0735-1097(02)02937-6

36. Onishi T, Onishi T, Marek JJ, Ahmed M, Haberman SC, Oyenuga $\mathrm{O}$, et al. Mechanistic features associated with improvement in mitral regurgitation after cardiac resynchronization therapy and their relation to long-term patient outcome. Circ Heart Fail. (2013) 6:685-93. doi: 10.1161/CIRCHEARTFAILURE.112.000112

37. van der Bijl P, Kostyukevich MV, Khidir M, Ajmone Marsan N, Delgado V, Bax JJ. Left ventricular remodelling and change in left ventricular global longitudinal strain after cardiac resynchronization therapy: prognostic implications. Eur Heart J Cardiovasc Imaging. (2019) 20:11129. doi: 10.1093/ehjci/jez072

38. Packer M, Grayburn PA. Contrasting effects of pharmacological, procedural, and surgical interventions on proportionate and disproportionate functional mitral regurgitation in chronic heart failure. Circulation. (2019) 140:77989. doi: 10.1161/CIRCULATIONAHA.119.039612

39. Gertz ZM, Raina A, Saghy L, Zado ES, Callans DJ, Marchlinski FE, et al. Evidence of atrial functional mitral regurgitation due to atrial fibrillation: reversal with arrhythmia control. J Am Coll Cardiol. (2011) 58:147481. doi: 10.1016/j.jacc.2011.06.032

40. Martens P, Deferm S, Bertrand PB, Verbrugge FH, Ramaekers J, Verhaert $\mathrm{D}$, et al. The detrimental effect of RA pacing on LA function and clinical outcome in cardiac resynchronization therapy. JACC Cardiovasc Imaging. (2020) 13:895-906. doi: 10.1016/j.jcmg.2019.04.022

41. Dell'Era G, Rondano E, Franchi E, Marino PN, Novara Atrial Fibrillation (NAIF) Study Group. Atrial asynchrony and function before and after electrical cardioversion for persistent atrial fibrillation. Eur J Echocardiogr. (2010) 11:577-83. doi: 10.1093/ejechocard/jeq010

42. Marrouche NF, Brachmann J, Andresen D, Siebels J, Boersma L, Jordaens L, et al. Catheter ablation for atrial fibrillation with heart failure. $N$ Engl J Med. (2018) 378:417-27. doi: 10.1056/NEJMoa1707855

43. Bortone A, Pujadas-Berthault P, Karam N, Maupas E, Boulenc JM, Rioux P, et al. Catheter ablation in selected patients with depressed left ventricular ejection fraction and persistent atrial fibrillation unresponsive to current cardioversion. Europace. (2013) 15:1574-80. doi: 10.1093/europace/eut088

44. Kawaji T, Shizuta S, Aizawa T, Yamagami S, Kato M, Yokomatsu T, et al. Impact of catheter ablation for atrial fibrillation on cardiac disorders in patients with coexisting heart failure. ESC Heart Fail. (2021) 8:6709. doi: $10.1002 / \mathrm{ehf} 2.13160$

45. Wu JT, Zaman JAB, Yakupoglu HY, Vennela B, Emily C, Nabeela K, et al. Catheter ablation of atrial fibrillation in patients with functional mitral regurgitation and left ventricular systolic dysfunction. Front Cardiovasc Med. (2020) 7:596491. doi: 10.3389/fcvm.2020.596491

46. Zhou X, Otsuji Y, Yoshifuku S, Yuasa T, Zhang H, Takasaki K, et al. Impact of atrial fibrillation on tricuspid and mitral annular dilatation and valvular regurgitation. Circ J. (2002) 66:913-6. doi: 10.1253/circj. 66.913

47. Paniagua D, Aldrich HR, Lieberman EH, Lamas GA, Agatston AS. Increased prevalence of significant tricuspid regurgitation in patients with transvenous pacemakers leads. Am J Cardiol. (1998) 82:1130-2. doi: 10.1016/S0002-9149(98)0 0567-0
48. Massie BM, Kramer BL, Topic N. Acute and long-term effects of captopril on left and right ventricular volumes and function in chronic heart failure. Am Heart J. (1982) 104:1197-203. doi: 10.1016/0002-8703(82)90051-5

49. Quaife RA, Christian PE, Gilbert EM, Datz FL, Volkman K, Bristow MR. Effects of carvedilol on right ventricular function in chronic heart failure. Am J Cardiol. (1998) 81:247-50. doi: 10.1016/S0002-9149(97)00874-6

50. Markman TM, Plappert T, De Feria Alsina A, Levin M, Amankwah N, Sheth S, et al. Improvement in tricuspid regurgitation following catheter ablation of atrial fibrillation. J Cardiovasc Electrophysiol. (2020) 31:28838. doi: 10.1111/jce.14707

51. Wang J, Li S, Ye Q, Ma X, Zhao Y, Han J, et al. Catheter ablation or surgical therapy in moderate-severe tricuspid regurgitation caused by long-standing persistent atrial fibrillation. Propensity score analysis. J Cardiothorac Surg. (2020) 15:277. doi: 10.1186/s13019-020-01336-3

52. Vahanian A, Beyersdorf F, Praz F, Milojevic M, Baldus S, Johann B, et al. $2021 \mathrm{ESC} / \mathrm{EACTS}$ guidelines for the management of valvular heart disease. Eur Heart J. (2021). doi: 10.1093/eurheartj/ehab395. [Epub ahead of print].

53. Karam N, Stolz L, Orban M, Deseive S, Praz F, Kalbacher D, et al. Impact of right ventricular dysfunction on outcomes after transcatheter edge-to-edge repair for secondary mitral regurgitation. JACC Cardiovasc Imaging. (2021) 14:768-78. doi: 10.1016/j.jcmg.2020.12.015

54. Karam N, Mehr M, Taramasso M, Besler C, Ruf T, Connelly KA, et al. Value of echocardiographic right ventricular and pulmonary pressure assessment in predicting transcatheter tricuspid repair outcome. JACC Cardiovasc Interv. (2020) 13:1251-61. doi: 10.1016/j.jcin.2020.02.028

55. Orban M, Karam N, Lubos E, Kalbacher D, Braun D, Deseive S, et al. Impact of proportionality of secondary mitral regurgitation on outcome after transcatheter mitral valve repair. JACC Cardiovasc Imaging. (2021) 14:71525. doi: 10.1016/S0735-1097(20)31739-3

56. Karam N, Braun D, Mehr M, Orban M, Stocker TJ, Deseive S, et al. Impact of transcatheter tricuspid valve repair for severe tricuspid regurgitation on kidney and liver function. JACC Cardiovasc Interv. (2019) 12:141320. doi: $10.1016 /$ j.jcin.2019.04.018

57. Mehr M, Karam N, Taramasso M, Ouarrak T, Schneider S, Lurz P, et al. Combined tricuspid and mitral versus isolated mitral valve repair for severe MR and TR: an analysis from the TriValve and TRAMI registries. JACC Cardiovasc Interv. (2020) 13:543-50. doi: 10.1016/j.jcin.2019.10.023

58. Goldstein DJ, Naka Y, Horstmanshof D, Ravichandran AK, Schroder J, Ransom J, et al. Association of clinical outcomes with left ventricular assist device use by bridge to transplant or destination therapy intent: the multicenter study of MagLev technology in patients undergoing mechanical circulatory support therapy with HeartMate 3 (MOMENTUM 3) randomized clinical trial. JAMA Cardiol. (2020) 5:411-9. doi: 10.1001/jamacardio.2019.5323

59. Goldstein DI, Naka Y, Horstmanshof D, Ravichandran AK, Schroder J, Ransom J, I et al. Destination therapy intent: the multicenter study of MagLev technology in patients undergoing mechanical circulatory support therapy with HeartMate 3 (MOMENTUM 3) randomized clinical trial. JAMA Cardiol. (2020) 5:411-9.

60. Topilsky Y, Oh JK, Atchison FW, Shah DK, Bichara VM, Schirger JA, et al. Echocardiographic findings in stable outpatients with properly functioning HeartMate II left ventricular assist devices. J Am Soc Echocardiogr. (2011) 24:157-69. doi: 10.1016/j.echo.2010.12.022

61. Potapov EV, Antonides C, Crespo-Leiro MG, Combes A, Färber G, Hannan MM, et al. 2019 EACTS expert consensus on long-term mechanical circulatory support. Eur J Cardiothorac Surg. (2019) 56:230-70. doi: 10.1093/ejcts/ezz098

62. Kanwar MK, Rajagopal K, Itoh A, Silvestry SC, Uriel N, Cleveland JC Jr, et al. Impact of left ventricular assist device implantation on mitral regurgitation: an analysis from the MOMENTUM 3 trial. $J$ Heart Lung Transplant. (2020) 39:529-37. doi: 10.1016/j.healun.2020. 03.003

63. Morgan JA, Paone G, Nemeh HW, Murthy R, Williams CT, Lanfear $\mathrm{DE}$, et al. Impact of continuous-flow left ventricular assist device support on right ventricular function. J Heart Lung Transplant. (2013) 32:398403. doi: 10.1016/j.healun.2012.12.018

64. Veen KM, Mokhles MM, Soliman O, de By TMMH, Mohacsi P, Schoenrath F, et al. Clinical impact and 'natural' course of uncorrected tricuspid regurgitation after implantation of a left ventricular assist 
device: an analysis of the European registry for patients with mechanical circulatory support (EUROMACS). Eur J Cardiothorac Surg. (2021) 59:20716. doi: 10.1093/ejcts/ezaa294

Conflict of Interest: The authors declare that the research was conducted in the absence of any commercial or financial relationships that could be construed as a potential conflict of interest.

Publisher's Note: All claims expressed in this article are solely those of the authors and do not necessarily represent those of their affiliated organizations, or those of the publisher, the editors and the reviewers. Any product that may be evaluated in this article, or claim that may be made by its manufacturer, is not guaranteed or endorsed by the publisher.

Copyright (c) 2021 Martin, Bories, Tence, Baudinaud, Pechmajou, Puscas, Marijon, Achouh and Karam. This is an open-access article distributed under the terms of the Creative Commons Attribution License (CC BY). The use, distribution or reproduction in other forums is permitted, provided the original author(s) and the copyright owner(s) are credited and that the original publication in this journal is cited, in accordance with accepted academic practice. No use, distribution or reproduction is permitted which does not comply with these terms. 